\title{
Warranties, performance, and the resolution of buyer-seller disputes
}

\author{
Thomas Palfrey* \\ and \\ Thomas Romer**
}

Many disputes between buyers and sellers concern product quality and whether a claim of poor product performance is covered by a warranty issued by the seller. We develop an analytical framework in which average product quality, buyer preferences, production and transaction costs, and the extent to which "true" quality can be observed by buyer and seller interact to determine warranties, product price, and the likelihood of disputes. Using this framework, we examine the impact of various types of dispute resolution mechanisms (DRM's) on these outcomes. We relate features of DRM's, such as cost and accuracy, to prices, warranties, and allocative efficiency of the market in which disputes arise.

\section{Introduction}

Mechanisms to resolve consumer disputes have been a major focus of the call for alternative ways to deal with relatively small disputes. Considerable energy has been spent documenting the consequences of not having adequate means to resolve disputes between buyers and sellers (Best and Andreasen, 1977; Nader, 1979). A fairly large literature has arisen that discusses the pros and cons of various attempts to deal with these problems. ${ }^{1}$ Municipal, state, and federal agencies have made consumer dispute resolution a matter of policy interest. ${ }^{2}$

A basic premise of our research is that to study the resolution of disputes properly, one must take into account the effect of the dispute resolution mechanism (DRM) on the actual occurrence of disputes and on the environment in which the original transactions take place. To do this, a theory in which disputes arise within the framework of

* Carnegie-Mellon University.

** Carnegie-Mellon University.

We thank two anonymous referees, the Journal's Editorial Board, and participants in seminars at CarnegieMellon University, Tulane University, and the Federal Trade Commission for helpful comments. We are particularly grateful to Dennis Epple for alerting us to the problems posed by the "no warranty, repurchase" option. This research was supported, in part, by NSF Grant SES82-08397.

${ }^{1}$ The bibliography by Sander and Snyder (1979) includes 28 entries on consumer disputes.

${ }^{2}$ To take just one example, consider the Federal Trade Commission. Under the Magnuson-Moss Act, the FTC has a mandate to encourage the development and implementation of mechanisms to resolve consumer disputes. FTC Rule 703 (16 CFR 703) defines the requirements a firm must satisfy if it specifies a dispute resolution mechanism as part of a warranty. The FTC staff has compiled a booklet that intends to assist companies in setting up such mechanisms (FTC, 1980a). In cases ranging from land sales (Great Western United Corp., 81 FTC 661 (1972)) to household furniture (Walker-Thomas Furniture Co., 87 FTC 26 (1976)), the Commission has made participation in a dispute resolution mechanism (typically use of the Better Business Bureau) part of the settlement decree. In a recent policy review session on Post-Purchase Remedies, consumer dispute resolution was prominently featured (FTC, 1980b). 
the model is needed. Although it is often recognized that the nature of the DRM available if there is a dispute may well affect the likelihood of disputes as well as their ultimate outcomes, systematic analysis of such interactions is scarce. ${ }^{3}$ We believe that an understanding of the interaction between DRM's and the environment in which they operate is essential if we are to answer questions about the desirability of encouraging or imposing particular types of DRM's.

The variety of buyer-seller disputes is enormous, ranging from those caused by false advertising and unfair sales practices to the collection of unpaid debts of credit card users. Our focus, however, is narrower. This article addresses a type of dispute that arises in conjunction with guaranteed products: disputes over warranty performance. Simply stated, a consumer seeks performance under a warranty contract and the seller refuses to perform. More specifically, our approach deals with warranties that insure the characteristics of a good or service at the time of sale. Most commonly, the characteristics in question are referred to as quality or durability. Warranties of this type exist because the buyer is unable to ascertain the relevant characteristics of the good before purchase. The warranty contract simply stipulates that the consumer will receive compensation if the characteristics of the good at the time of purchase are $x$ and will not receive compensation if the characteristics of the good at time of purchase are not $x$.

A major problem arises in contracts of this sort. When a claim for compensation is made by the consumer, it may not be possible to observe without error whether the characteristics of the good or service at the time of sale were $x^{4}{ }^{4}$ This may render enforcement of the contract difficult, if not impossible. In such cases, one would expect disputes to arise naturally between buyers and sellers, with buyers seeking performance of the contract and sellers claiming that the contract does not apply. This difference of opinion can occur even when the seller is acting in good faith. In the model we present here, purely fraudulent behavior on the part of the seller is explicitly excluded. It is, then, a theory of "good faith" disputes.

To keep matters simple, we consider a good that can have only two possible quality levels-high or low. The seller sets a price and offers the good for sale under one of three possible warranty policies-no warranty, conditional warranty, or unconditional warranty. After purchase, a buyer observes a noisy signal about the quality of the unit, which provides (imperfect) information that the unit is either likely to be high quality or likely to be low quality. The buyer has a claim strategy or decision rule that maps the price, the warranty, and the noisy signal into a decision either to keep the unit as it is, to make a claim under the warranty, or simply to purchase a new unit.

Claim procedures are costly, so that if a buyer initiates a claim, he incurs some cost and imposes a (possibly different) cost on the seller. If a buyer makes a claim under a warranty, the seller observes a noisy signal (possibly different from that received by the buyer) about whether the warranty applies. If the seller decides on the basis of this information that the warranty does not apply, he refuses the claim, and we say that a dispute has occurred. (divorce).

${ }^{3}$ But see Mnookin and Kornhauser (1979) for an analysis in this spirit, though in a very different setting

${ }^{4}$ Moreover, the true quality at the time the claim is made may not even be observable without error. For example, if the good is a durable, there is no reason to believe that the entire future stream of services that the good will provide the buyer is perfectly known. Alternatively, there may be uncertainty about the meaning of the warranty itself. For example, limited warranties often say that the product is guaranteed to last a certain length of time as long as "the instructions for use are carefully followed." Such conditions are not only unobservable, but they may even be vacuous (in the sense that such limitations may be legally forbidden). Warranty contracts often contain such clauses, some of which may have no legal basis, some of which involve unobservable events, and some of which are written in complicated "legalese." This suggests that uncertainty arises because the buyer (and perhaps even the seller) does not know the condition that determines when a remedy is required. 
Although in some respects our framework for analyzing product quality, information, and warranties follows that of the recent economics literature, we deviate from the standard approach in an important way. In the usual models of warranties and product quality, either the buyer or the seller is assumed to be able to ascertain perfectly the quality of the product when a warranty claim is made. ${ }^{5}$ There can be no good faith disputes in such markets-and, in fact, these models never consider the question of warranty performance. In our framework, use of the product may provide a buyer with more information about the quality of the good than he had at the time of purchase, but still does not yield perfect information about true quality. Similarly, inspection by the seller when a claim is made makes the seller more informed than he was before but still leaves some uncertainty. Consequently, disputes arise endogenously in our framework.

In the absence of relatively inexpensive ways to resolve such disputes, the seller's word is typically the last one. In Section 2 we analyze this "no DRM" situation and characterize market outcomes in the absence of any third-party mechanism to resolve disputes. We examine the following questions in the context of a simple model of a product market with warranties. What type of warranty will be offered? What will be the price? How is the price related to the warranty? When will disputes occur? How efficient are the market outcomes? The answers depend, in a systematic way, on such factors as production and transaction costs, buyer preferences, and the degree of information imperfections.

We explore this dependence in Section 3, and we illustrate it by characterizing the equilibrium as a function of underlying variables for a particular value of average product quality. We find that in equilibrium disputes will arise over a wide range of buyer preferences, production and inspection costs, and informativeness of buyer and seller signals about true quality. If inspection costs are very high, we find, not surprisingly, that warranties will not be offered. Although one might expect that warranty coverage is most extensive when inspection costs are very low, we find that this is not necessarily the case. Very low inspection costs can lead to an equilibrium in which no warranty is offered.

Section 4 extends the model in a natural way to include dispute resolution mechanisms to which buyers may appeal if disagreements arise. The arguments for various dispute resolution mechanisms are generally based on the expectation that such mechanisms will enhance the well-being of participants in the market. Our framework allows us to focus on many of the attributes that most writers on dispute resolution have deemed important characteristics of DRM's: cost, allocation of cost between parties, accuracy of outcome, and tendency to bias. ${ }^{6}$ Through a number of examples, we highlight a surprisingly broad range of possible outcomes. We find that mechanisms for resolving disputes may indeed have significant effects on the warranty that is offered and the price at which the commodity is sold. These effects can result in either an increase or reduction of overall market efficiency, even if the DRM is procedurally "perfect." In particular, we find that

\footnotetext{
${ }^{5}$ Recent contributions to the study of warranties when there are imperfections in information include Appelbaum and Scheffman (1980), Courville and Hausman (1979), Simon (1981), and Spence (1977), to name only a few. The models used by these authors are not set up in a way that allows examination of questions relating to buyer-seller disputes. In all these models, once a claim is made, all uncertainty is resolved. Hence there is no possibility for disputes to arise. Informational considerations focus on consumers' lack of knowledge or their "misperceptions" about average quality, and warranties are a means of raising buyers' estimates of average quality. This is in contrast to our model, in which buyer and seller both have the same (correct) information about average quality, but true quality is not fully known by either party when a claim is made. Enforcement of a warranty is, consequently, no longer a clear-cut matter.

The approach of Simon (1981) comes closest to ours. She allows the consumer to retain some uncertainty about seller liability before making a claim. In other respects, Simon's model is quite different from ours. For example, Simon has the warranty exogenously fixed by law and defined in terms of guaranteed average quality. Also, as with the other models, there is no possibility for disputes over the validity of a warranty claim.

${ }^{6}$ See Johnson (1978) for a thorough discussion of these and other attributes of DRM's.
} 
a DRM that is costless, perfectly accurate, and not biased in favor of either buyer or seller can reduce market efficiency, even though it may both reduce the number of disputes and increase the extent of warranty coverage offered by the seller in equilibrium. The reason for this conflict between procedural and efficiency considerations is that a DRM can have adverse incentive effects on buyer claim strategies. When this is the case, costly, inaccurate, and biased procedures may produce superior market performance. Because of such effects, a DRM cannot simply be evaluated on the basis of such intrinsic qualities as "fairness," accuracy, or direct cost to the disputing parties. Nor can these judgments be based only on whether a DRM causes a stronger warranty to be offered or how the likelihood of disputes is affected. ${ }^{7}$

The article concludes with a section that briefly discusses some important aspects of the warranty framework and points toward possibilities for its further application and extension.

\section{Warranty equilibrium without a mechanism to resolve disputes but in which disputes are possible}

- Consider an environment in which a single seller faces a (potentially large) number of consumers. ${ }^{8}$ The seller has access to or can produce unlimited quantities of a commodity at constant unit cost $c$. The quality of a given unit of this commodity is either high or low. The a priori probability that any unit is of high quality is exogenously fixed at $t$, and the probability of low quality is $1-t$. These probabilities are independent of the qualities of other units. We shall often refer to a high quality unit as "good" and to a low quality unit as "bad."

Buyers are assumed to be identical in their valuation of the commodity. Each buyer values (in dollar terms) a high quality unit at $V_{h}$ and a low quality unit at $V_{l}$. Without loss of generality, we shall assume that $V_{l}=0$.

Buyers and seller are risk neutral. This allows us to focus on those aspects of the problem that have to do with the information structure, rather than attitude toward risk.

Before a unit is purchased, neither buyer nor seller has any specific information about an individual unit's true quality, but the probability $t$ is common knowledge to all parties. Once a buyer has purchased a unit, he gains some information about the true quality of the object. This is modeled in the following way. Upon purchasing a unit and using it for a short period of time, a buyer judges whether the quality is high, which will generate a stream of value over time equal to $V_{h}$, or low, which will generate a stream of value over time of 0 . Sometimes this judgment is correct and sometimes it is wrong. The probability that the buyer judges quality correctly is $q$, and this probability is independent of true quality. ${ }^{9}$

The buyer may return the object to the seller, in exchange for some form of compensation conditional on the quality of the unit. If an object is returned to the seller, the seller makes a judgment about the quality of the unit. As was the case with the buyer,

\footnotetext{
${ }^{7}$ The central role of imperfect information on the parts of both buyers and seller should be self-evident at this point. For an excellent discussion and survey of general policy questions relating to consumer product markets when there is imperfect information, see Schwartz and Wilde (1979). Although we do not consider the same set of specific issues they considered, very broadly speaking we do adopt a similar strategy for analyzing the problem. That is, our approach involves an examination of the interactions among: (a) market equilibrium (i.e., prices, qualities, and warranties); (b) informational considerations; (c) institutional environment (DRM's in our case); and (d) incentives generated for market participants.

${ }^{8}$ The model may also be applied to competitive markets with many sellers. The monopoly case has the virtue of simplicity: it is a useful vehicle for displaying the framework.

${ }^{9}$ More generally, we could allow the buyer to be more likely to err when true quality is high than when it is low, or vice versa. This involves only a notational modification of our framework.
} 
the seller does not make perfect judgments. The probability that the seller judges a unit correctly is $q$-the same as the probability that the buyer makes a correct judgment. ${ }^{10}$

Transaction costs are an important element of our model. We assume that in making a purchase the buyer incurs a shopping $\operatorname{cost} c_{b}$ in addition to the price. Processing claims under a warranty typically involves the investment of time and valuable resources by both buyer and seller. To capture this, we introduce a return cost to the buyer, which we take to be equal to $c_{b}$, and a claim cost to the seller, $c_{s}$. Each time a buyer makes a claim, the buyer incurs cost $c_{b}$ and the seller incurs cost $c_{s}$, regardless of the outcome of the warranty claim.

Buyers and seller know all the probabilities, as well as the cost and value parameters. This completes the information structure in this model. A feature of this framework which differentiates it from previous literature on the subject is that it permits imperfect judgment of quality. Neither buyer nor seller is a perfect quality assessor. They make judgments independently of each other. Sometimes both are right, sometimes the buyer is right and the seller is wrong, sometimes the seller is right and the buyer is wrong, and sometimes both are wrong.

In this context, two types of warranty seem natural: money-back guarantees and replacement policies. With a money-back guarantee, the buyer is returned the purchase price of the unit if a claim is made and the seller agrees that the claim is a valid one. With a replacement policy the buyer is given a new unit if a claim is made and the seller agrees that the claim is a valid one. For each type of warranty we distinguish between an unconditional (which we refer to as "full") warranty and a conditional (which we refer to as "partial") warranty. With an unconditional warranty the seller always agrees that the buyer's claim is valid; there are "no questions asked." With a conditional warranty, the seller promises to perform only if the unit is a bad one. ${ }^{11}$ The seller's behavior with conditional warranties is to inspect the unit if a claim has been made and then to honor the claim if the inspection tells the seller it is a bad unit but to refuse the claim if inspection indicates it is not a bad unit. ${ }^{12}$ The probability that the seller finds a unit defective is determined by the probability $q$.

If the seller does replace a unit after a claim has been made, the original warranty offered with the first unit also applies to the new replacement unit. Thus, the whole procedure described above repeats itself until either the buyer is satisfied (i.e., does not make a claim) or the seller refuses a claim. This recursive structure is modeled explicitly in our analysis.

Given the assumptions of our model-especially the assumption that the quality of different units is drawn independently from a given (identical) distribution which is known to the buyer-it turns out that a money-back guarantee is essentially the same as a replacement policy. Suppose a buyer finds it advantageous to buy one unit, finds it defective, returns it, and gets his money back. Because of independence, there is no reason

\footnotetext{
${ }^{10}$ The seller, too, could be allowed to err differentially according to true quality. Moreover, the probabilities of buyer error could be different from the probabilities of seller error. In our exposition we have chosen to simplify the parameter structure by capturing buyer and seller perceptions with the single variable $q$, rather than the four variables that would be needed if buyer and seller did not have common and symmetric perceptions of quality.

${ }^{11}$ We caution the reader that our use of the terms "partial" and "full" warranties does not necessarily coincide with their standard legal definitions. The "fullness" of the warranties in our model refers to the range of (apparent) product qualities they cover-not to the extent of compensation in the event the warranty is found to apply. As an anonymous referee has pointed out, our framework could readily allow for the analysis of warranties that offer less than full compensation (e.g., partial refunds), though we do not pursue this here.

${ }^{12}$ Under what we call a Full Warranty, the "customer is always right," so that the seller need not inspect. This may make his claim processing cost less than $c_{s}$. Replacing $c_{s}$ by a parameter $c_{s}^{\prime}<c_{s}$ would not alter the general character of our analysis. We have chosen to use the same $c_{s}$ as the seller's claim cost under Full Warranty and Partial Warranty to avoid adding more parameters.
} 
for him still not to find it advantageous to buy a second unit. Thus the buyer is indifferent between a replacement or a return of the purchase price. The seller is also indifferent between the two. In either case, the buyer will end up with a replacement and the seller will incur the unit production cost. Because of this essential equivalence, all of the subsequent analysis is done with reference to the replacement type of warranty.

We should point out that our formulation excludes the possibility that a seller might offer a warranty and then always refuse claims, regardless of the outcome of the inspection. Our primary intent is to focus on disputes that may emerge because of the imperfections of information, rather than on disputes resulting from purely fraudulent behavior. In the context of our model, unless a DRM exists, a warranty that was always refused would be a vacuous warranty. Since buyers are assumed to be aware of seller behavior, they would ascribe zero value to warranties that are never honored. Alternatively, we could interpret the seller's parameter $q$ (which is known to buyer and seller alike) simply as a variable that characterizes the seller's behavior. Whether this represents "honest" perceptions is not particularly important. What matters is that buyer and seller both act as if this probability represents the seller's judgment of the quality of a returned unit.

$\square$ Definition of equilibrium. With this characterization of the market, we proceed as follows. A buyer takes the price of a unit of the commodity and the warranty policy (Full Warranty, Partial Warranty, or No Warranty) offered by the seller as given. He chooses the best response; i.e., the action that maximizes the expected value, net of transaction costs, he gets from this market. This involves a decision whether to buy and, if he buys, how to act under the warranty. The buyer's choices include: never return a unit; return regardless of his judgment about quality; return only if he perceives his unit to be of low quality; or discard the unit and repurchase. ${ }^{13}$ These decisions generate a response function for a buyer. The seller takes this response function as given, and chooses the price and warranty policy that maximize the expected profit or seller's surplus-the difference between expected revenue and expected cost. We shall call the outcome of this interaction between buyer and seller the equilibrium in this market.

In addition to characterizing price and type of warranty, we are interested in the relative efficiency of the equilibrium. This involves looking at the total expected surplus that obtains. Naturally, there remain important distributional questions (who gets the expected surplus) that this focus on total expected surplus does not answer.

Calculation of buyer's expected valuations and seller's expected costs under different warranties. The buyer's expected valuations under various warranty policies can be derived quite readily. In the following expressions, we define these valuations as being gross of price-i.e., the buyer's expected surplus is equal to these valuations minus price. Equivalently, these expected valuations are, in each case, the most that a buyer would be willing to pay to buy the commodity if he were faced with the given warranty policy and followed the stated warranty claim strategy.

Five cases are of interest. We now define each case and for each one, we calculate the buyer's expected valuations. Denote the buyer's expected valuation in these cases as $V_{0}, V_{1}, V_{2}, V_{3}$, and $V_{4}$, respectively.

Because of the relatively simple recursive structure of our model, it is a straightforward

${ }^{13}$ An equivalent way of interpreting a buyer's return strategy is to view it as a reservation (or "cutoff") level that specifies a minimum perceived quality below which the buyer will choose to return or to repurchase. The fact that, in our model, a high reservation level necessarily has the buyer returning the unit regardless of perceived quality is simply a result of the binary nature of the signal the buyer observes about quality. Returning a unit regardless of perceived quality should just be interpreted as having a high reservation level; never returning units as having a low reservation level; and returning only perceived bad units as having an intermediate reservation level. 
exercise to write recursion formulas for these expected valuations and to solve them directly. It is useful to solve first for $v$, the buyer's expected valuation gross of shopping cost $c_{b}$. In each case, then

$$
V=v-c_{b}
$$

Case (A): No Warranty. Buyer never returns or repurchases commodity. $\left(V_{0}\right)$. Since $V_{l}=0$, we have

and

$$
v_{0}=t V_{h}
$$

$$
V_{0}=t V_{h}-c_{b}
$$

Case (B): No Warranty. Buyer never returns, but discards perceived low-quality unit and buys new unit. $\left(V_{1}\right)$. If $p$ is the price of a unit, a recursive expression for $v_{1}$ is the following:

$$
v_{1}=t q V_{h}+[t(1-q)+(1-t) q]\left(v_{1}-p-c_{b}\right) \text {. }
$$

The first term is the value of consuming a high quality unit times the probability the purchased unit is correctly judged by the consumer to be high quality. The second term is the probability the unit is judged by the consumer to be low quality times the ex ante value of a new unit net of the cost of repurchase, $v_{1}-p-c_{b}$. The first term corresponds to the event "buyer perceives high quality and does not repurchase," while the second term corresponds to the event "buyer perceives low quality, discards unit, and buys a new unit."

Solving for $v_{1}$ and taking $V_{1}=v_{1}-c_{b}$ give:

$$
V_{1}=\frac{t q V_{h}-c_{b}-[t+q(1-2 t)] p}{t q+(1-t)(1-q)} .
$$

Case (C): Full Warranty. Buyer returns (i.e., makes a claim under the warranty) if he perceives low quality. $\left(V_{2}\right)$. A recursive expression for $v_{2}$ is

so that

$$
v_{2}=t q V_{h}+[t(1-q)+(1-t) q]\left(v_{2}-c_{b}\right),
$$

$$
V_{2}=v_{2}-c_{b}=\frac{t q V_{h}-c_{b}}{t q+(1-t)(1-q)} .
$$

Case (D): Partial Warranty. Buyer returns if he perceives low quality. $\left(V_{3}\right)$. The recursive expression for $v_{3}$ is:

$v_{3}=t q V_{h}+[t(1-q)+(1-t) q]\left[\frac{t(1-q)^{2}+(1-t) q^{2}}{t(1-q)+(1-t) q} v_{3}+\frac{t q(1-q)}{t(1-q)+(1-t) q} V_{h}-c_{b}\right]$.

The first term in this expression is the same as the first term for the previous case. The second term, however, now has three components: a component corresponding to the event "seller replaces unit;" a component corresponding to the event "seller refuses claim;" and the return cost, $c_{b}$. The first component is the probability that the seller perceives that the unit is low quality, conditional on the buyer perceiving that the unit is low quality,

$$
\frac{t(1-q)^{2}+(1-t) q^{2}}{t(1-q)+(1-t) q}
$$

times the values to the buyer of the replacement unit $\left(v_{3}\right)$. The second component is the probability that the seller correctly perceives that the unit is high quality, conditional on the buyer perceiving that the unit is low quality,

$$
\frac{t q(1-q)}{t(1-q)+(1-t) q}
$$


multiplied by the value of a good unit $\left(V_{h}\right)$. Solving for $V_{3}$ yields:

$$
V_{3}=v_{3}-c_{b}=\frac{t q(2-q) V_{h}-[1+q(1-q)] c_{b}}{1-[t+q(q-2 t)]} \text {. }
$$

Case (E): Partial Warranty. Buyer always returns. $\left(V_{4}\right)$. The recursive expression for $v_{4}$ is:

$$
v_{4}=-c_{b}+t q V_{h}+[t(1-q)+(1-t) q] v_{4} .
$$

These three terms are, respectively, the return cost, $c_{b}$ : the expected value to the buyer if the seller refuses his claim; and the expected value to the buyer if the seller replaces the unit. Solving for $V_{4}$ yields:

$$
V_{4}=v_{4}-c_{b}=\frac{t q V_{h}-[1+t q+(1-t)(1-q)] c_{b}}{t q+(1-t)(1-q)} .
$$

For each of these cases, we can use similar techniques to derive the expected costs to the seller. These valuations and costs are summarized in Table 1.

The entries corresponding to "Full Warranty, Always Return," "No Warranty, Always Return," "No Warranty, Return Perceived Low Quality," "Partial Warranty, Never Return," and "Full Warranty, Never Return," are purposely omitted from the table. "Full Warranty, Always Return," yields infinite losses to both parties. "No Warranty, Always Return" and "No Warranty, Return Perceived Low Quality" are both dominated by "No Warranty, Never Return." Finally, "Partial Warranty, Never Return" and "Full Warranty, Never Return" are equivalent to "No Warranty, Never Return." Equilibria in these boxes either would be equivalent to other equilibria or would never occur.

Table 1 also lacks entries for situations when, under a warranty, the buyer chooses to repurchase-i.e., discard a unit and buy a new one, either before, after, or instead of

\begin{tabular}{|c|c|c|c|}
\hline & Full Warranty & Partial Warranty & No Warranty \\
\hline $\begin{array}{l}\text { Return All } \\
\text { Units }\end{array}$ & 1. & $\begin{array}{l}\text { 5. } \\
\frac{t q V_{h}-[1+t q+(1-t)(1-q)] c_{b}}{t q+(1-t)(1-q)} \\
\frac{c+c_{s}}{t q+(1-t)(1-q)}\end{array}$ & 9. \\
\hline $\begin{array}{l}\text { Return } \\
\text { Perceived } \\
\text { Low Quality }\end{array}$ & $\begin{array}{l}\text { 2. } \\
\frac{t q V_{h}-c_{b}}{t q+(1-t)(1-q)} \\
\cdots-\cdots \\
\frac{c+[t+q(1-2 t)] c_{s}}{t q+(1-t)(1-q)}\end{array}$ & $\begin{array}{l}6 . \\
\frac{t q(2-q) V_{h}-[1+q(1-q)] c_{b}}{1-[t+q(q-2 t)]} \\
\quad \frac{c+[t+q(1-2 t)] c_{s}}{1-[t+q(q-2 t)]}\end{array}$ & 10. \\
\hline $\begin{array}{l}\text { Discard Low } \\
\text { Quality and } \\
\text { Repurchase }\end{array}$ & 3. & 7. & $\begin{array}{l}\frac{11 .}{t q V_{h}-c_{b}-[t+q(1-2 t)] p} \\
t q+(1-t)(1-q) \\
\frac{c}{t q+(1-t)(1-q)}\end{array}$ \\
\hline $\begin{array}{l}\text { Never Return } \\
\text { or Repurchase }\end{array}$ & 4. & 8. & $\begin{array}{l}\text { 12. } \\
\qquad \begin{array}{l}t V_{h}-c_{b} \\
c\end{array}\end{array}$ \\
\hline
\end{tabular}
returning the original to the seller. It can be shown that this repurchase option is of no

TABLE 1 Summary of Costs and Valuations*

\footnotetext{
* Buyer expected valuations (above dashed lines) and seller expected costs (below dashed lines).
} 
consequence when the equilibrium involves a warranty. ${ }^{14}$ Hence, the five cases of Table 1 cover all the interesting possibilities.

In terms of Table 1, equilibrium corresponds to the box that yields the seller highest expected profit subject to a very important constraint. If the seller offers a warranty, he cannot compel the buyer to follow a particular claim strategy. The buyer chooses the claim strategy that is in his own best interest-i.e., yields the highest expected value for the buyer. Figuratively, the seller chooses the column in Table 1, but the buyer chooses the row, given the seller's choice of column and the seller's price. The seller takes this into account in formulating his warranty policy.

Under a Full Warranty, the highest price the seller can charge is

$$
p_{\max }^{F}=V_{2} \text {. }
$$

The maximum expected profit under a Full Warranty is

$$
\pi_{\text {max }}^{F}=V_{2}-\frac{c+[t+q(1-2 t)] c_{s}}{t q+(1-t)(1-q)} .
$$

If a Partial Warranty is offered, the seller's expected profit depends on whether the buyer always returns or returns only units he thinks are bad. If the buyer always returns, then under a Partial Warranty the seller's maximum expected profit is

$$
\pi_{\text {max }}^{P A}=V_{4}-\frac{c+c_{s}}{t q+(1-t)(1-q)} .
$$

For values of $q$ and $t$ between 0 and 1 ,

$$
\pi_{\max }^{F}>\pi_{\max }^{P A} .
$$

Consequently, the seller would always do better by offering a Full Warranty rather than a Partial Warranty if under the Partial Warranty the buyer would always return. As a result, "Partial Warranty, Always Return" cannot be an equilibrium. Thus, if a Partial Warranty is offered in equilibrium, the buyer would be choosing the "Return Perceived Bad Units" strategy. The seller would charge a price equal to $V_{3}$.

Consider next the situation when No Warranty is offered. The buyer would not return or repurchase $\left(V_{0}>V_{1}\right)$ if and only if

$$
p>\tilde{p}=\frac{t(1-t)(2 q-1) V_{h}}{t+q(1-2 t)}-c_{b} .
$$

If, however, $p<\tilde{p}$, the buyer would opt to repurchase when he thinks he has a bad unit $\left(V_{1}>V_{0}\right)$. The seller's maximum expected revenue when he offers No Warranty depends, in turn, on which strategy the buyer chooses. If the buyer chooses "No Return, No Repurchase," the maximum price is

$$
p_{\max }^{N}=V_{0}>\tilde{p}
$$

and the seller's maximum expected profit is

$$
\pi_{\max }^{N}=t V_{h}-c_{b}-c .
$$

The seller's maximum expected profit under "No Warranty, Buyer Repurchases Perceived Bad Units" is

$$
\pi_{\max }^{N R}=\frac{\tilde{p}-c}{t q+(1-t)(1-q)} .
$$

\footnotetext{
${ }^{14}$ A proof is contained in Palfrey and Romer (1982), which is available from the authors upon request.
} 
If the seller chooses the "No Warranty" policy, he has two options: charge price $\tilde{p}$ or $p_{\max }^{N}>\tilde{p}$, depending on which leads to higher expected profit.

To summarize, the possible equilibrium price-warranty combinations are:

(1) Full Warranty $(F): p=p_{\max }^{F}=V_{2}$ (buyer returns perceived bad units);

(2) Partial Warranty $(P l): p=p_{\max }^{P l}=V_{3}$ (buyer returns perceived bad units);

(3) No Warranty $(N): p=p_{\max }^{N}=V_{0}$ (buyer never returns, never repurchases);

(4) No Warranty (NR): $p=\tilde{p}$ (buyer repurchases, discards perceived bad units).

There is, of course, also the uninteresting "No Sale" equilibrium (no strategy earns positive expected profit for the seller and nonnegative expected value for the buyer).

In the first three types of equilibrium, the seller captures all the expected surplus. In contrast, it is interesting that in the fourth type of equilibrium, the monopolist is forced to yield some expected surplus to the buyer, since $\tilde{p}<V_{1}$ for any $t$ and $q$ between 0 and 1. Which equilibrium prevails depends on the values of the parameters $t, q, V_{h}, c, c_{b}$, and $c_{s}$.

For a given set of parameter values we can characterize the "efficient" outcome as the price-warranty combination that maximizes expected total surplus $S$ : the sum of buyer's expected surplus and seller's expected profit. Some equilibria are efficient in this sense, while others are not. In particular, Full Warranty is never an efficient equilibrium when the seller's inspection cost $c_{s}$ is positive. To see this, note that expected total surplus under Full Warranty is:

$$
S^{F}=\left(V_{2}-p\right)+p-\frac{c+[t+q(1-2 t)] c_{s}}{t q+(1-t)(1-q)}=\frac{t q V_{h}-c_{b}-c-[t+q(1-2 t)] c_{s}}{t q+(1-t)(1-q)} .
$$

Under "No Warranty, Buyer Repurchases" $(N R)$, expected total surplus is:

$$
S^{N R}=V_{1}-p+\frac{p-c}{t q+(1-t)(1-q)}=\frac{t q V_{h}-c_{b}-c}{t q+(1-t)(1-q)}
$$

and, for $c_{s}>0$,

$$
S^{N R}>S^{F}
$$

Nevertheless, $N R$ may not be an equilibrium, given individual maximization by seller and buyer.

In the next section, we illustrate these and other points by providing a complete characterization of warranty equilibrium for the case of $t=.5$. We also restrict our attention to cases in which $q>.5$; i.e., both buyer and seller are more likely to perceive quality correctly than to err.

\section{Warranty equilibrium with $t=.5$ and $q>.5$}

With $t=.5$, the entries in Table 1 simplify nicely, so that this is a particularly easy case to analyze. (The qualitative relationships of this section apply for any $t$, but prices and the "boundaries" that separate warranty regimes depend on the value of $t$.) For expositional purposes it is useful to depict the price-warranty equilibria in terms of the various cost parameters. In Figures 1 through 3, we fix the values of all parameters other than the buyer's transaction cost $c_{b}$, and depict price-warranty combinations as a function of $c_{b}$.

There are three basic patterns of equilibria in this representation, according to whether

or

(a) $c_{s}<(1-q) V_{h}$

or

$$
\text { (b) }(1-q) V_{h}<c_{s}<(1-q) V_{h}+2 q(1-q) c
$$

(c) $c_{s}>(1-q) V_{h}+2 q(1-q) c$. 
(a) $c_{s}<(1-q) V_{h}$. In this case, the seller's inspection cost is relatively low; and for any $c_{b}, \pi_{\max }^{F}>\pi_{\max }^{N R}$, so that $N R$ is never an equilibrium. When the buyer's return cost $c_{b}$ is low, the buyer is willing to pay a high price for a Full Warranty, relative to the seller's expected cost for such a warranty, so that Full Warranty is the equilibrium. When $c_{b}$ is high, the buyer's willingness to pay for a warranty is considerably reduced because of the high expected return cost. At a low price, however, the seller is unwilling to offer a warranty. The equilibrium is No Warranty (buyer never returns or repurchases). For intermediate values of $c_{b}$, the seller finds it profitable to offer a Partial Warranty. The buyer returns units he thinks are of low quality, and disputes are possible.

This case is illustrated in Figure 1 . The values $k_{1}$ and $k_{2}$ that determine the boundaries for warranty types are defined in the Appendix. If $k_{1} \leq 0$, there can be no Full Warranty equilibrium, while if $k_{2} \leq 0$, only No Warranty equilibrium (or No Sale) can occur.

(b) $(1-q) V_{h}<c_{s}<(1-q) V_{h}+2 q(1-q) c$. This case is similar to (a), except that the seller's warranty processing cost $c_{s}$ is sufficiently high that, for $c_{b} \geq 0, \pi_{\max }^{N R}>\pi_{\max }^{F}$, and Full Warranty is never an equilibrium. Now, at low values of $c_{b}$, the seller maximizes expected profit by offering No Warranty, at a relatively low price. Because both price and transaction cost are low, the buyer is willing to discard units he thinks are of low quality and repurchase. This yields $N R$ as the equilibrium. When the buyer's transaction cost is high, however, even a low price is not sufficient to induce repurchase, so that the equilibrium is No Warranty, with no return or repurchase. At intermediate values of $c_{b}$, the equilibrium is once again Partial Warranty (buyer returns units he thinks are bad), at a relatively high price.

Figure 2 illustrates this case. Again, $k_{3}$ and $k_{2}$ are defined in the Appendix, and for $k_{3} \leq 0$, an $N R$ equilibrium cannot exist.

(c) $c_{s}>(1-q) V_{h}+2 q(1-q) c$. When the seller's inspection cost is high, there can be no equilibrium in which a warranty is offered. Regardless of $c_{b}$, the cost to the seller of processing claims makes warranties relatively unattractive to him. As in case (b), when the buyer has low transaction cost, the seller offers No Warranty, at a price sufficiently low for the buyer to repurchase after discarding perceived bad units. As $c_{b}$ rises, however, the seller would have to keep reducing price to induce such behavior. For sufficiently high $c_{b}$, the seller does better by raising price. The equilibrium becomes No Warranty, with no return or repurchase.

This case is shown in Figure 3. The critical value $k_{4}$ is defined in the Appendix. If $k_{4} \leq 0$, then only a No Warranty, No Repurchase or a No Sale equilibrium is possible.

\section{FIGURE 1}

PRICE-WARRANTY EQUILIBRIUM WHEN $\mathrm{t}=.5, \mathrm{c}_{\mathrm{s}}<(1-\mathrm{q}) \mathrm{V}_{\mathrm{h}}$

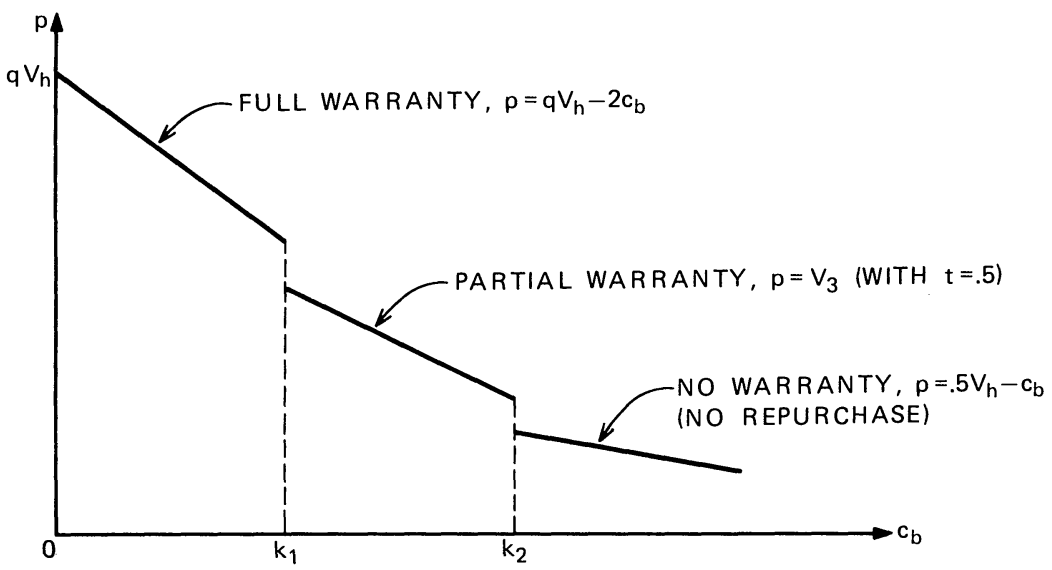


FIGURE 2

PRICE-WARRANTY EQUILIBRIUM WHEN $\mathrm{t}=.5,(1-\mathrm{q}) \mathrm{V}_{\mathrm{h}}<\mathrm{c}_{\mathrm{s}}<(1-\mathrm{q}) \mathrm{V}_{\mathrm{h}}+2 \mathrm{q}(1-\mathrm{q}) \mathrm{c}$

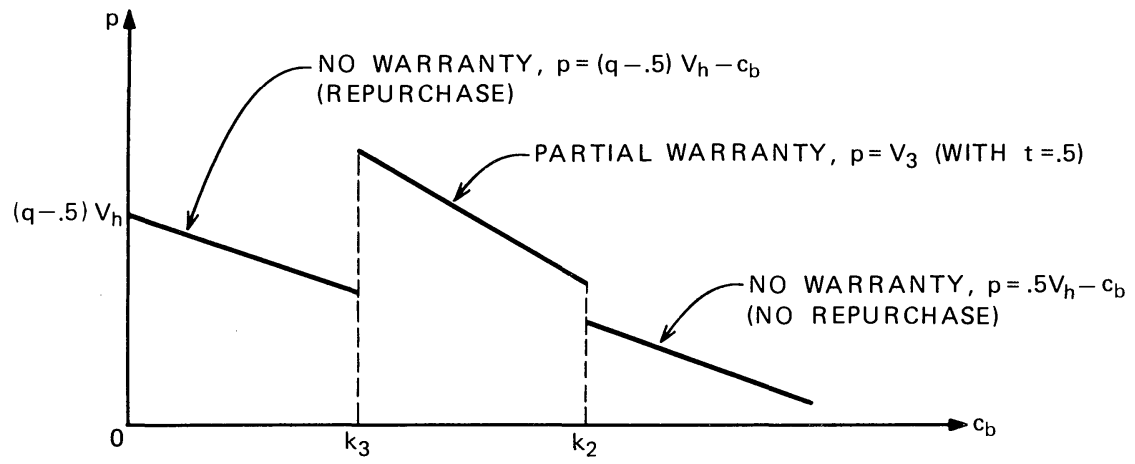

Examples of warranty equilibrium. The following numerical examples illustrate several outcomes, including the possibility that the equilibrium is not efficient-i.e., does not maximize expected surplus. These examples also provide a useful basis for the discussion in the next section, where they will reappear in our examination of DRM's.

Example (1). $t=.5, q=.75, c=4, c_{b}=4, c_{s}=2, V_{h}=30$. The equilibrium is $N o$ Warranty. Buyer never returns or repurchases. Price is 11 , and expected total surplus $(=7)$ is maximized, given the information structure.

Example (2). $t=.5, q=.75, c=4, c_{b}=3, c_{s}=1, V_{h}=30$. The equilibrium is Partial Warranty. The buyer makes a claim if he thinks he has a bad unit. The seller refuses a claim if he thinks the unit is good (i.e., its condition is "not covered by the warranty"). Price is 15.27 . In this example, the equilibrium price-warranty combination maximizes expected total surplus $(=8.73)$, given the information structure.

Example (3). $t=.5, q=.75, c=4, c_{b}=1, c_{s}=2, V_{h}=30$. Maximum expected total surplus occurs in Box 11 of Table 1 (No Warranty, Repurchase), with $p=6.5$. At this price-warranty combination, the buyer's expected surplus is 7.5 and the seller's expected profit is 5.0. The seller can do better, however, by offering a Full Warranty at $p=20.5$, thereby getting expected profit of 10.5 (which is also the expected total surplus). This equilibrium is inefficient.

Example (4). $t=.5, q=.75, c=4.5, c_{b}=1, c_{s}=1, V_{h}=20$. Maximum expected total surplus occurs in Box 6 of Table 1 (Partial Warranty, Buyer Returns Units He Perceives Are Bad), with $p=11.91$ and $S=4.64$. If the seller offers a Partial Warranty, however,

FIGURE 3

PRICE-WARRANTY EQUILIBRIUM WHEN $\mathrm{t}=.5, \mathrm{c}_{\mathrm{s}}>(1-\mathrm{q}) \mathrm{V}_{\mathrm{h}}+2 \mathrm{q}(1-\mathrm{q}) \mathrm{c}$

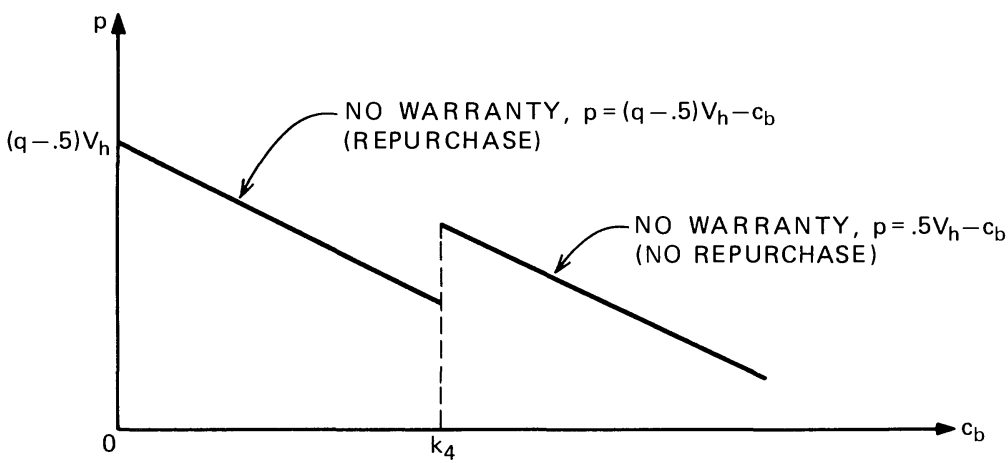


the buyer's best claim strategy is to return all units. Returning all units yields the buyer higher expected value under Partial Warranty in this case than does returning only those he thinks are bad. If Partial Warranty is offered, therefore, the seller's expected profit is what he gets in Box 5. Expected profit is maximized in Box 12, which is the equilibrium: No Warranty, Buyer Never Returns or Repurchases. Price is 9, and expected total surplus is 4.5 .

Because neither party observes quality perfectly, and the seller cannot "force" the buyer into the box that is best for the seller, examples (3) and (4) show that in some cases the "first-best" solution is not an equilibrium. We stress that we are not talking about "first-best" relative to a full-information setting. The equilibria in examples (3) and (4) are inefficient, in the sense of not maximizing total expected surplus, relative to the imperfect information structure of the market. In these examples, the warranty is either "too strong," as in Example (3) or "too weak," as in Example (4). In the next section we introduce a framework to explore the effects of different dispute resolution mechanisms in mitigating (or worsening) these potential inefficiencies.

\section{Inclusion of third-party mechanism to resolve disputes over warranty performance}

- In our model disputes about warranties can arise naturally through the workings of the marketplace. Whenever Partial Warranty is the equilibrium, buyer and seller can potentially disagree about warranty performance. Suppose we now extend the framework to allow for a third party (neither buyer nor seller) to adjudicate these disputes. How does the availability of such a mechanism affect the market? What happens to warranties, the likelihood of disputes, the price of commodities, the expected surplus? How do these effects depend on attributes of the marketplace and the dispute resolution mechanism?

This section proposes a way to characterize DRM's in terms of cost and information.

We describe several exemplary mechanisms in these terms and illustrate the range of possible effects of these mechanisms in a series of examples.

The DRM we have in mind would work as follows. Since potential disputes arise whenever a seller denies a buyer's claim under a Partial Warranty, it seems appropriate to structure the problem so that the buyer has the option of taking the dispute to the DRM for resolution. If the buyer appeals, the DRM makes a decision whether the seller must perform under the warranty. If the DRM agrees with the buyer, the seller must comply. To close the model, we assume there are no avenues of appeal beyond the DRM, nor are there costs of enforcing the DRM's decisions. In each dispute, the DRM's decision is final. We continue to allow for the possibility that the seller performs under his warranty (either without an appeal having taken place or because he is directed to do so by the DRM), replacing the unit with a new one which may, in turn, be returned by the buyer, etc. Thus, the recursive nature of the formal structure is retained even with the inclusion of a DRM.

One can imagine a great variety of possibilities for characterizing a DRM in more complete terms. We would like to abstract from the internal workings of the mechanism. We shall not elaborate the process the third party uses to gather evidence or make a judgment. Instead, we shall characterize a DRM by three important types of parameters: those relating to the mechanism's cost; those relating to the mechanism's precision in making judgments; and those relating to any bias of the mechanism. These parameters capture the important considerations we identified in the Introduction.

The resource cost of operating a DRM must be taken into account in any evaluation of such processes. Moreover, the way the cost is divided between the two parties may substantially alter the incentives and hence the mechanism's effects. In our notation, $c_{m}$ denotes the cost of the mechanism (per appeal). The proportion of this cost borne by the 
consumer is $\alpha$, and $\beta$ is the proportion of this cost borne by the seller. We do not require that $\alpha+\beta=1$. The mechanism could be subsidized by society as a whole $(\alpha+\beta<1)$ or, instead, buyer and seller together may be required to pay more than the marginal cost of a dispute $(\alpha+\beta>1)$.

Other important aspects of a DRM are defined by two parameters, $q_{h}^{m}$ and $q_{l}^{m}$, which are, respectively, the probability that the mechanism rules in favor of the buyer when the unit is actually high quality (i.e., an erroneous judgment) and the probability that the mechanism rules in favor of the buyer when the unit is actually low quality (i.e., a correct judgment). ${ }^{15}$

Using these parameters, we may define the precision $\phi$ of a mechanism as the probability of making a correct judgment, given that a dispute has arisen. This will generally depend on which return strategy the buyer follows. Two cases should be distinguished. In Case 1, the buyer always returns units under a partial warranty, and the buyer appeals all disputes. Case 2 applies when the buyer returns all units but appeals a dispute only if he perceived that the unit was low quality. Case 2 also applies when the buyer returns only units he perceives as low quality and appeals all disputes. Precision is then given by:

$$
\phi= \begin{cases}\frac{t q\left(1-q_{h}^{m}\right)+(1-t)(1-q) q_{l}^{m}}{t q+(1-t)(1-q)} & \text { in Case } 1 \\ t\left(1-q_{h}^{m}\right)+(1-t) q_{l}^{m} & \text { in Case } 2\end{cases}
$$

In Case 2, $\phi$ is conditioned on the fact that the buyer has perceived the unit to be of low quality.

One way to define the bias $\theta$ of a mechanism is as the probability of erring in the buyer's favor minus the probability of erring in the seller's favor. Thus, if $\theta>0$, the mechanism is biased in favor of the buyer, while if $\theta<0$, the bias is in the seller's favor. As with precision, the bias will generally depend on the buyer's return and appeal strategy:

$$
\theta= \begin{cases}\frac{t q q_{h}^{m}-(1-t)(1-q)\left(1-q_{l}^{m}\right)}{t q+(1-t)(1-q)} & \text { in Case } 1 \\ t q_{h}^{m}-(1-t)\left(1-q_{l}^{m}\right) & \text { in Case } 2 .\end{cases}
$$

Note that $-1 \leq \theta \leq 1$, and that an unbiased mechanism has $\theta=0$ for both cases.

One can approximate a wide range of procedures by different values of $q_{h}^{m}$ and $q_{l}^{m}$. Some interesting possibilities (of admittedly varying degrees of reality) follow. The first two are mechanisms that bring additional information to bear on the decision. The others essentially reduce to deciding outcomes by tossing a weighted coin. Many other variations are possible.

(1) The full-scale investigation or omniscient mechanism: $q_{h}^{m}=0, q_{l}^{m}=1$. In this mechanism, the decision is always correct. The mechanism is perfectly precise and unbiased: $\phi=1$ and $\theta=0$ regardless of the buyer's return strategy. Of course, this is a polar case, but it is worth considering because it at least gives some bounds as to how good (in an informational sense) the procedure can be.

(2) The technical expert: $q_{h}^{m}=\hat{q}_{h}, q_{l}^{m}=\hat{q}_{l}$. A neutral outside expert, such as a second mechanic in the case of auto warranties or a construction engineer in the case of a home warranty, is called in to make a judgment. This judgment is assumed to be statistically independent of the judgment previously made by the seller's inspector and the buyer.

${ }^{15}$ Thus, the a priori probability that a DRM decides in favor of the buyer is $t q_{h}^{m}+(1-t) q_{l}^{m}$; the probability of deciding in favor of the seller is $t\left(1-q_{h}^{m}\right)+(1-t)\left(1-q_{l}^{m}\right)$. 
(3) The lay judge: $q_{h}^{m}=q_{l}^{m}=1-t$. A lay judge has neither the first-hand experience of the buyer, nor the expertise of the seller's inspector. The judge does, however, know the average quality of this type of product $(t)$. Therefore, this judge bases his decision only on the ex ante probability of the unit's being good. The mechanism is imprecise $(\phi<1$ for $t<1)$ and, for $q>.5$, it is biased in favor of the buyer in Case 1. (But $\theta=0$ in Case 2.)

(4) The judge of insufficient reason: $q_{h}^{m}=q_{l}^{m}=.5$. This judge ${ }^{16}$ has no information about the quality of the unit. He applies the principle of insufficient reason (i.e., all states are equally probable) and, in the interest of "fairness," rules in favor of the buyer just as often as he rules in favor of the seller. In fact, this mechanism is not only imprecise $(\phi=.5)$, but generally biased (in favor of the buyer if $t \geq .5, q>.5$ ).

The addition of a third party mechanism adds another stage to the sequence of decisions a buyer must make, and it adds one more possibility that the seller must take into account when choosing the warranty. The buyer has to decide whether to appeal if the seller refuses to grant his original claim. This decision may, of course, depend on the quality observed by the buyer.

This additional complexity does not make the problem intractable in our framework. Since disputes can occur only when a Partial Warranty is offered, a DRM changes only the values of Partial Warranty strategies-areas 5 and 6 of Table 1. The expected costs and buyer valuations under Full Warranty and No Warranty remain the same as in areas 2,11 , and 12 of Table 1.

By altering the relative values of different warranty policies, a DRM will affect the market outcome. Some DRM's may be efficiency-enhancing-that is, they may lead to higher expected surplus (net of the expected costs of the mechanism) than would be possible in their absence. Others may have the opposite effect-they may induce market allocations that are inferior to the no-mechanism outcome.

To provide an indication of this analysis, we consider briefly the special mechanism (1), viz., the Full Scale Investigation or Omniscient Mechanism, when the buyer bears no cost of the appeal process, so that $\alpha=0$. This example has illustrative appeal since it is a polar case in terms of both the precision of the mechanism (perfect) and the cost to the buyer (free). It is also particularly simple to work with, yet still admits every possible equilibrium. In Table 2, we indicate the expected seller costs and buyer valuations under this mechanism, with the additional assumption that $t=.5$. Since it can be shown that the buyer will appeal every dispute, we do not indicate in Table 2 the cases in which appeal is contingent on the quality perceived by the buyer.

This mechanism may, for some values of the parameters, create inefficiency even in markets where the no-DRM equilibrium was efficient. This can occur in a number of ways. Most obviously, if $c_{m}$ is sufficiently high, then even an omniscient mechanism can never improve on the no-mechanism equilibrium. A much more interesting and surprising result, however, is that even a costless $\left(c_{m}=0\right)$ omniscient mechanism may induce inefficiencies. This can occur in one of two ways. In one case, having this mechanism available moves the equilibrium from a partial warranty (in the absence of the mechanism) to a full warranty and in the other case, from a partial warranty (under no mechanism) to no warranty. The source of the problem is that under certain conditions the presence of an omniscient mechanism will induce a buyer to generate more disputes than he would have with no mechanism. As a result, the buyer will never end up with a low-quality product, but the seller will have to replace so many units that this more than offsets the surplus gain to the buyer. (Remember that the seller has no control over average product quality, $t$.)

\footnotetext{
${ }^{16}$ This has also been labelled The Unlearned Hand (courtesy of R. Craswell).
} 
TABLE 2 Buyer's Expected Values and Seller's Expected Costs for Omniscient Mechanism That Is Costless to the Buyer $(\alpha=0)$, with $t=.5$

\begin{tabular}{|c|c|c|c|}
\hline & $\begin{array}{c}\text { Full } \\
\text { Warranty }\end{array}$ & Partial Warranty & No Warranty \\
\hline $\begin{array}{l}\text { Always Return, Appeal } \\
\text { All Disputes }\end{array}$ & 1. & $\begin{array}{l}\text { 5. } \\
\qquad \frac{q V_{h}-(2+q) c_{b}}{q} \\
\quad \frac{2\left(c+c_{s}\right)+\beta c_{m}}{q}\end{array}$ & 9. \\
\hline $\begin{array}{l}\text { Return Only Perceived } \\
\text { Low Quality, Appeal } \\
\text { All Disputes }\end{array}$ & \begin{tabular}{l}
2. \\
$q V_{h}-2 c_{b}$ \\
\hdashline--- \\
$2 c+c_{s}$
\end{tabular} & $\begin{array}{l}6 . \\
\frac{q(2-q) V_{h}-[2+q(1-q)] c_{b}}{1+q(1-q)} \\
\quad \frac{2 c+c_{s}+2 q(1-q) \beta c_{m}}{1+q(1-q)}\end{array}$ & 10. \\
\hline $\begin{array}{l}\text { Discard Low Quality } \\
\text { and Repurchase }\end{array}$ & 3. & 7. & $\begin{array}{l}11 . \\
q V_{h}-2 c_{b}-p \\
---\cdots \\
2 c\end{array}$ \\
\hline $\begin{array}{l}\text { Never Return or } \\
\text { Repurchase }\end{array}$ & 4. & 8. & 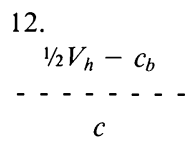 \\
\hline
\end{tabular}

To illustrate some of the possible outcomes, we repeat our earlier simple numerical examples (and add a new one), with the introduction of a costless omniscient mechanism. Example (1). $t=.5, q=.75, c=4, c_{b}=4, c_{s}=2, V_{h}=30$. A costless omniscient mechanism moves the equilibrium from No Warranty to Partial Warranty. Price rises to 16.32 and expected surplus to 7.89 .

Example (2). $t=.5, q=.75, c=4, c_{b}=3, c_{s}=1, V_{h}=30$. With the DRM, if a Partial Warranty is offered, the buyer always returns units and always appeals. The seller's expected profit is maximized by offering No Warranty, at $p=12$. The expected total surplus $(=8)$ is lower in the equilibrium with the DRM than it was in the mechanism's absence.

Example (2a). $t=.5, q=.75, c=5, c_{b}=4, c_{s}=1, V_{h}=41$. With no DRM, the equilibrium is Partial Warranty, price is 21.05 , and expected surplus is 13.05 . The buyer returns units he perceives are of low quality. With a costless, omniscient DRM, if a partial warranty is offered, the buyer always returns units and always appeals disputes. Now the seller's expected profit is maximized by offering a Full Warranty at $p=22.75$. The expected total surplus $(=11.75)$ is lower with the DRM than it would be with no DRM.

Example (3). $t=.5, q=.75, c=4, c_{b}=1, c_{s}=2, V_{h}=30$. The introduction of a DRM has no effect on the equilibrium or on the maximum expected surplus. A Full Warranty is offered and the mechanism is never used.

In Example (1), the existence of a DRM not only increases surplus, but it leads to an equilibrium where disputes occur, when in the absence of the DRM no disputes took place. In Examples (2) and (2a), however, a costless, omniscient DRM induces inefficiency. In these cases, the existence of an omniscient DRM increases the buyer's willingness to return units, so that all units would be returned under a partial warranty. This increases the frequency of disputes. The seller avoids the increased cost of having more frequent disputes under a partial warranty with a DRM by offering no warranty at all (as in Example (2)) or by offering a Full Warranty (as in Example (2a)) so that disputes cannot occur. 
As a foil for the omniscient mechanism, we have also computed equilibria for the costless Lay Judge DRM, with $t=.5$. With the costless omniscient mechanism, it cannot be optimal for the buyer not to appeal disputes if he makes returns under Partial Warranty. With the costless Lay Judge and $t=.5$, it is possible for some parameter values that the buyer returns units but does not appeal disputes. With this additional consideration, we derive buyer valuations and seller costs for the costless Lay Judge. For Examples (1) and (3), the equilibrium is the same under this DRM as with no mechanism. In Example 2, however, the costless Lay Judge DRM results in a Partial Warranty equilibrium in which the buyer returns units he thinks are low quality and appeals all disputes. Price is 15.79 and expected surplus is 8.21. Although expected surplus is lower than with no DRM at all, it is higher than under the costless omniscient mechanism. In Example (2a), the costless Lay Judge DRM also leads to a Partial Warranty equilibrium, with the buyer returning perceived low quality units and appealing all disputes. Price is 25.76 and expected surplus is 16.5 , which is higher than with no DRM or with the costless omniscient mechanism.

The focus on costless mechanisms has the virtue of isolating the incentive and welfare effects of the informational content of different DRM's. It neglects, however, two additional important considerations: the cost of the mechanism and how this cost is divided between buyer and seller. Absolute cost and the division of costs have different effects. Absolute cost affects primarily the surplus corresponding to any buyer strategy under partial warranty. The allocation of DRM cost between buyer and seller affects the equilibrium warranty, but (for given total cost) does not change the surplus corresponding to each possible warranty-buyer strategy combination.

These effects are clearly seen by considering a costly omniscient mechanism. The analysis is quite similar to the costless case, except that three additional buyer strategies are now possible with partial warranties. The additional strategies (which are never optimal when the mechanism is costless or $\alpha=0$ ) are:

(1) Buyer returns all units and appeals no disputes;

(2) Buyer returns all units and appeals a dispute only if he perceived the unit to be low quality; and

(3) Buyer returns only perceived low quality units and appeals no disputes.

The resulting table of buyer expected values and seller expected costs differs only in the Partial Warranty column. These new values and costs for $t=.5$ are given in Table 3 .

Inspection of Table 3 reveals that increasing $\alpha c_{m}$ induces the buyer to avoid disputes, either by leading him to create disputes less frequently (i.e., return only perceived low quality units) or by leading him to appeal fewer of the disputes that actually occur. This can increase efficiency of the equilibrium for the following reason. The costless mechanism may result in surplus loss because it induces the buyer to engage in dispute creating behavior (i.e., always return under partial warranty). This imposes externalities on the seller, causing the seller to avoid disputes completely by offering either no warranty or a full warranty. A mechanism that is costly to the buyer functions as a tax that internalizes this externality.

Recall that in example (2), a costless omniscient mechanism resulted in a surplus loss. In the same example, a costly omniscient mechanism can lead to a surplus gain (say, if $\alpha=\beta=.5, c_{m}=5$ ) relative to no mechanism and relative to the "free" omniscient mechanism. For very large costs, say $\alpha=\beta=.5$ and $c_{m}=20$, the omniscient mechanism will duplicate the no mechanism outcome, since disputes will never be appealed.

\section{Discussion and conclusion}

- In the product quality problem we analyzed, warranties and prices provide quality control in the marketplace. This function can be viewed as a type of "noisy" insurance, 
TABLE 3 Buyer's Expected Values and Seller's Expected Costs under Partial Warranty for Omniscient Mechanism, with $t=.5$

\begin{tabular}{|c|c|}
\hline Always Return, Appeal All Disputes & $\frac{q V_{h}-(2+q) c_{b}-\alpha c_{m}}{q}$ \\
\hline $\begin{array}{l}\text { Always Return, Appeal Disputes } \\
\text { Only If Perceived Low Quality }\end{array}$ & $\begin{array}{c}\frac{q V_{h}-[3-q(1-q)] c_{b}-2 q(1-q) \alpha c_{m}}{1-q(1-q)} \\
\frac{2 c+2 c_{s}+2 q(1-q) \beta c_{m}}{1-q(1-q)}\end{array}$ \\
\hline Always Return, Never Appeal & $\begin{array}{c}q V_{h}-3 c_{b} \\
2 c+2 c_{s} \\
2 \ldots \ldots\end{array}$ \\
\hline $\begin{array}{l}\text { Return Only Perceived Low Quality, } \\
\text { Appeal All Disputes }\end{array}$ & $\begin{array}{c}\frac{q(2-q) V_{h}-[2+q(1-q)] c_{b}-2 q(1-q) \alpha c_{m}}{1+q(1-q)} \\
\frac{2 c+c_{s}+2 q(1-q) \beta c_{m}}{1+q(1-q)}\end{array}$ \\
\hline $\begin{array}{l}\text { Return Only Perceived Low Quality, } \\
\text { Never Appeal }\end{array}$ & $\begin{array}{c}\frac{q(2-q) V_{h}-2[1+q(1-q)] c_{b}}{1+2 q(1-q)} \\
\frac{2 c+c_{s}}{1+2 q(1-q)}\end{array}$ \\
\hline
\end{tabular}

although it differs from the usual notion of insurance because it does not provide any risk-sharing role, since all agents are risk neutral. "Claims" are not always legitimate (i.e., buyers may return high-quality goods when they are only insured for low-quality goods) because informational imperfections do not permit the contracting parties to distinguish perfectly between legitimate and illegitimate claims. Quality is not perfectly observable. Furthermore, legitimate claims are not always honored, again because of informational imperfections (as opposed to purely fraudulent behavior). Nonetheless, legitimate claims are more likely to be made and are more likely to be honored than illegitimate claims.

Because of informational imperfections, full insurance is not possible in the model. If quality were perfectly and costlessly observable, then the (risk-neutral) buyer could fully self-insure by repurchasing until he gets a good unit. Warranties would, at best, provide superfluous insurance. With imperfect information, this is no longer so. A full warranty provides only a single screening of quality (only the buyer screens the unit). The same is true with no warranty. A partial warranty provides a double screening of quality (both the buyer and the seller screen the unit for quality). Partial warranties may therefore provide better average quality than full or null warranties. This does not mean that partial warranties will always be better. If screening (i.e., buyers making claims and sellers processing claims) is costly, then a partial warranty may be quite costly relative to no warranty or full warranty. This cost depends on the degree of informational imperfection as well as the actual costs of making and processing claims. Consequently, the efficient warranty depends on all these factors.

The efficient warranty need not coincide with the equilibrium. One reason for this is that the seller can only partially control the buyer's returning policy by varying prices and by offering different warranties. A partial warranty may be the efficient warranty if the buyer returns only perceived low-quality units. But if the seller is unable to induce 
the buyer to return only low-quality units under a partial warranty, then the equilibrium warranty could be full or null. An additional source of inefficiency in our model stems from the assumption that the seller is a monopolist. If "No Warranty, Buyer Repurchases Perceived Bad Units" is the efficient outcome, the seller is not able to extract all the consumer surplus because the price required to do this is so high that it will induce the buyer not to repurchase perceived bad units. If this is the case, the seller can sometimes do better by offering a full warranty and extracting all the surplus.

An important feature of our model is that good faith disputes, or disputes over fact, occur in equilibrium between buyer and seller, and the likelihood of these disputes varies systematically with the underlying parameters of the model. One of the motivations for our approach is to analyze the impact of alternative dispute resolution mechanisms. DRM's are typically set up to affect warranties, prices, the likelihood of a dispute, and (possibly) the distribution of surplus between buyer and seller. To compare the effect of different DRM's, we have formulated a model that generates disputes, that derives some linkages between disputes, prices, and warranties, and that makes it possible to relate these to the underlying product market.

The examples we use to illustrate the comparative effects of DRM's, while suggestive rather than conclusive, do indicate that the interaction of a DRM with a market where product quality is an important consideration is quite complex. Moreover, the effects of DRM's may be quite surprising and counterintuitive because of complicated effects on buyer and seller incentives. The observation that even an "ideal" (costless and omniscient) mechanism may be far from ideal-causing either too much or too little warranty protection-seems particularly striking.

Throughout the article, we made a number of simplifying assumptions. For example, we assumed that buyer and seller are risk neutral. One could allow for risk aversion, so that warranties would serve a risk-sharing role. This would tend to reinforce incentives already present to have warranties. Because risk aversion would also obfuscate the quality control role of warranties, we took agents to be risk neutral. Additional quality levels or a quality continuum might add some realism to the model and provide a richer variety of possible warranty contracts. We expect that the basic relationships among prices, extent of warranty, and the parameters of the market would not change dramatically with the introduction of more than two quality levels.

A particularly strong assumption is that the seller has no direct control over average "intrinsic" quality, $t$. We know that the type of warranty policy that emerges is sensitive to this parameter, with or without a DRM. We expect that, were it not too costly, the firm might choose to adjust quality control or prescreen specific units to affect buyer claim strategies. If so, then an additional impact of a DRM would be to alter average intrinsic quality at the time of sale. Incorporating such effects would be a useful elaboration of our model.

Moving further afield from the central concern of our analytical framework, we believe there is an important set of phenomena involving legal/economic interactions that may potentially be addressed from the perspective of this model. Given the uncertainty present in most economies, contractual arrangements often involve specific references or contingencies that are inherently not observable with certainty. Because of this, whether conditions of a contract have been satisfied cannot always be treated as a clearcut event. One party may feel that the contract has been performed, while the other may not. In such situations, the particular institutions used to resolve disputes may be very important in determining contractual form and economic allocation. The simple warranty environment examined here is but one example. The type of analysis we have outlined can be adapted to evaluate different contractual contexts, and can lead to insights about the efficiency of the contractual arrangements, as well as the efficacy of different appeals procedures designed to resolve the disputes over "fact" that will naturally arise. 


\section{Appendix}

- Let

$$
\begin{aligned}
& a_{0}=\frac{q V_{h}(2 q-1)(1-q)}{1+4 q(1-q)} \\
& a_{1}=(q-.5) V_{h}-\left(2 c+c_{s}\right) \\
& a_{2}=(q-.5) V_{h}-\left(c+c_{s}\right) \\
& a_{3}=(q-.5) V_{h}-[1-2 q(1-q)] c-c_{s} \\
& b_{1}=\frac{-(1-q)^{2}(1+4 q) V_{h}-4 q(1+q) c+c_{s}}{2 q(1-q)} \\
& b_{2}=(2 q-1.5) V_{h}-c .
\end{aligned}
$$

If $c_{b}<a_{0}$, then $V_{4}>V_{3}$ : buyer always returns under Partial Warranty.

Define

Then

$$
\pi_{\max }^{P l}=\frac{q(2-q) V_{h}-2[1+q(1-q)] c_{b}-2 c-c_{s}}{1+2 q(1-q)} .
$$

$$
\begin{aligned}
& c_{b}<a_{1} \Rightarrow \pi_{\text {max }}^{F}>\pi_{\text {max }}^{P l} \\
& c_{b}<a_{2} \Rightarrow \pi_{\text {max }}^{F}>\pi_{\text {max }}^{N} \\
& c_{b}<a_{3} \Rightarrow \pi_{\text {max }}^{P l}>\pi_{\text {max }}^{N} \\
& c_{b}<b_{1} \Rightarrow \pi_{\text {max }}^{N R}>\pi_{\text {max }}^{P l} \\
& c_{b}<b_{2} \Rightarrow \pi_{\text {max }}^{N R}>\pi_{\text {max }}^{N} .
\end{aligned}
$$

Reversing the inequalities on the left reverses the inequalities on the right.

The parameters $k_{1}, k_{2}, k_{3}$, and $k_{4}$ in Figures $1-3$ are defined as follows:

$$
\begin{aligned}
& k_{1}=\min \left[a_{2}, \max \left(a_{0}, a_{1}\right)\right] \\
& k_{2}=a_{3} \\
& k_{3}=\min \left[b_{2}, \max \left(a_{0}, b_{1}\right)\right] \\
& k_{4}=b_{2}
\end{aligned}
$$

Under Case (a) (i.e., $\left.c_{s}<(1-q) V_{h}\right)$, the following variation on Figure 1 holds when $a_{2}<a_{0}<a_{3}$ :

$$
\begin{array}{lll}
\text { Full Warranty } & \text { if } & c_{b} \leq a_{2} \\
\text { No Warranty (No Repurchase) } & \text { if } & a_{2}<c_{b} \leq a_{0} \\
\text { Partial Warranty } & \text { if } & a_{0}<c_{b} \leq a_{3} \\
\text { No Warranty (No Repurchase) } & \text { if } & c_{b}>a_{3} .
\end{array}
$$

Under Case (b) (i.e., $\left.(1-q) V_{h}<c_{s}<(1-q) V_{h}+2 q(1-q) c\right)$, the following variation on Figure 2 holds when $b_{2}<a_{0}<a_{3}$ :

$$
\begin{array}{ll}
\text { No Warranty (Repurchase) } & \text { if } c_{b} \leq b_{2} ; \\
\text { No Warranty (No Repurchase) } & \text { if } \quad b_{2}<c_{b} \leq a_{0} \text {; } \\
\text { Partial Warranty } & \text { if } \quad a_{0}<c_{b} \leq a_{3} \text {; } \\
\text { No Warranty (No Repurchase) } & \text { if } \quad c_{b}>a_{3} .
\end{array}
$$




\section{References}

ApPelbaum, E. And SchefFman, D. "Product Reliability, Warranties and Producer Liability, and Advertising." Federal Trade Commission Working Paper, 1980.

Best, A. AND ANDreasen, A.R. "Consumer Response to Unsatisfactory Purchases: A Survey of Perceiving Defects, Voicing Complaints, and Obtaining Redress." Law and Society Review (Spring 1977).

COURVille, L. AND Hausman, W. "Warranty Scope and Reliability under Imperfect Information and Alternative Market Structures." Journal of Business (1979).

Federal Trade Commission. Handling Consumer Complaints: In-House and Third-Party Strategies. Washington, D.C., 1980a.

. Post-Purchase Remedies. Briefing Book for Policy Review Session. Washington, D.C., 1980b.

Johnson, E., JR. A Preliminary Analysis of Alternative Strategies for Processing Civil Disputes. National Institute for Law Enforcement and Criminal Justice, U.S. Department of Justice, Washington, D.C., 1978.

MNOOKIN, R.H. AND KORNhAuSER, L. "Bargaining in the Shadow of the Law." Yale Law Journal (April 1979).

NADER, L. "Disputing without the Force of Law." Yale Law Journal (April 1979).

PAlfREY, T. AND ROMER, T. "Warranties, Performance, and the Resolution of Buyer-Seller Disputes." GSIA Working Paper No. 32-81-82, Carnegie-Mellon University, July 1982.

SANDER, F.A. AND SNyDER, F.E. Alternative Methods of Dispute Settlement-A Selected Bibliography. Washington, D.C.: American Bar Association, 1979.

SCHWARTZ, A. AND WILDE, L. "Intervening in Markets on the Basis of Imperfect Information: A Legal and Economic Analysis." University of Pennsylvania Law Review (1979).

SIMON, M. "Imperfect Information, Costly Litigation, and Product Quality." Bell Journal of Economics (Spring 1981).

SPENCE, A.M. “Consumer Misperceptions, Product Failure, and Producer Liability." Review of Economic Studies (October 1977). 